\title{
Maternal anaemia and its effects on neonatal anthropometric parameters in patients attending a tertiary care institute of Solan, Himachal Pradesh, India
}

\author{
Manisha Behal $^{1}$, Rajeev Vinayak ${ }^{2 *}$, Anuj Sharma ${ }^{3}$
}

\begin{abstract}
${ }^{1}$ Department of Obstetrics and Gynecology, ${ }^{2}$ Department of Pediatrics, ${ }^{3}$ Department of Pathology, Maharishi
\end{abstract} Markandeshwar Medical College and Hospital, Solan, Himachal Pradesh, India

Received: 21 November 2017

Revised: 23 December 2017

Accepted: 26 December 2017

\section{*Correspondence: \\ Dr. Rajeev Vinayak, \\ E-mail: rsjevx69pro@gmail.com}

Copyright: (C) the author(s), publisher and licensee Medip Academy. This is an open-access article distributed under the terms of the Creative Commons Attribution Non-Commercial License, which permits unrestricted non-commercial use, distribution, and reproduction in any medium, provided the original work is properly cited.

\begin{abstract}
Background: Anaemia during pregnancy is a significant concern in India. The consequences of iron deficiency anaemia during pregnancy are often serious and long lasting for both the mother and the foetus. Haematocrit measurement is an acceptable and recommended method for anaemia determination especially in situations where limited resources are available, and the technical support is poor. There is a rough conversion factor of 3 which converts the HCT value to approximate haemoglobin level. Present study desires to know the prevalence of anaemia (with classification into mild, moderate and severe) in $3^{\text {rd }}$ trimester pregnancy, to know effect of anaemia in pregnancy on new-born anthropometric parameters and to assess the validity of the threefold conversion between haemoglobin and haematocrit for the determination of anaemia in pregnancy.

Methods: The estimation of haematocrit was done by micro-haematocrit method and estimation of haemoglobin was done by automated blood cell analyzer based on cyanmethemoglobin method. Welch's ANOVA, Post Hoc games Howell test and Bland Altman limits of agreement method were used for statistical analysis.

Results: Present study showed that $53.75 \%$ women in their $3^{\text {rd }}$ trimester were anaemic (mild, moderate and severe anaemic mothers were $22.25 \%, 28.25 \%$ and $3.25 \%$ respectively). The standard 3-fold conversion between the haemoglobin and haematocrit was not found to be valid for the assessment of anaemia in the 3rd trimester pregnancy. Finally, while comparing anthropometric measurements between mild/ no anaemia group with severe anaemia group we found that all measurements were less in severe anaemia group and this difference was statistically significant.

Conclusions: This study shows that $53.75 \%$ women in their 3rd trimester were anaemic, which closely mimic the WHO data but is about $11 \%$ more than the prevalence in Himachal Pradesh. Secondly, the standard 3-fold conversion between the haemoglobin and haematocrit was not found to be valid for the assessment of anaemia in the 3rd trimester pregnancy. Finally, birth weight, height, head circumference, chest circumference and mid-arm circumference were significantly affected by third trimester haemoglobin that too the most in severe anaemia cases.
\end{abstract}

Keywords: Anaemia, Pregnancy, Hematocrit, Hemoglobin

\section{INTRODUCTION}

Anaemia during pregnancy is a significant concern with the World Health Organization (WHO) estimating a prevalence of $54 \%, 39.3 \%$ and $38.2 \%$ amongst pregnant women in India, Asia and world respectively. ${ }^{1}$ In healthy, iron-sufficient women, haemoglobin $(\mathrm{Hb})$ concentrations change dramatically during pregnancy to accommodate the increasing maternal blood volume and the iron needs of the fetus. ${ }^{2}$ Currently, there are no WHO 
recommendations on the use of different haemoglobin cut-off points for anaemia by trimester, but it is recognized that during the second trimester of pregnancy, haemoglobin concentrations diminish approximately 0.5 $\mathrm{gm} / \mathrm{dl} .^{3}$ The WHO defines anaemia regardless of its cause as the presence of a $\mathrm{Hb}$ level of less than $11.0 \mathrm{gm} / \mathrm{dl}$ during pregnancy. ${ }^{3,4}$ Mild anaemia is defined as $\mathrm{Hb}$ between 10.0-10.9 gm/dl, moderate anaemia as 7.0-9.9 $\mathrm{gm} / \mathrm{dl}$ and severe anaemia as $<7 \mathrm{gm} / \mathrm{dl}^{3,5}$ The US Centres of Disease Control (CDC) recommendations take into account the observation that there is a trough in the physiological course of $\mathrm{Hb}$ during pregnancy. ${ }^{6}$ According to this definition, anaemia is present if the $\mathrm{Hb}$ level is less than $11 \mathrm{gm} / \mathrm{dl}$ during first trimester and third trimester of gestation, and less than $10.5 \mathrm{gm} / \mathrm{dl}$ during second trimester. These $\mathrm{Hb}$ levels correspond to haematocrit (Hct) values of 33.0, 32.0 and $33.0 \%$, respectively. ${ }^{5-7}$ The consequences of iron deficiency anaemia (IDA) during pregnancy are often serious and long lasting for both the mother and foetus. Expectant mothers with anaemia often experience increased fatigue levels, reduced exercise performance and reduced mental performance., ${ }^{8,9-11}$ Furthermore, severe anaemia is related to an increased risk of spontaneous abortions prematurity, small for gestational-age babies, intrauterine growth retardation, and neonatal death. ${ }^{8,12-14}$ Since early detection and effective management of anaemia in pregnancy contributes substantially to the reduction in maternal mortality and stillbirth rate, it is crucial that all pregnant women are screened for anaemia during pregnancy.

\section{Haemoglobin and haematocrit}

The $\mathrm{Hb}$ provides a direct measure of the oxygen carrying capacity of the blood, whereas the Hct provides an indirect one. The $\mathrm{Hb}$ estimates the erythrocytic function and is more stable to plasma volume changes such as dehydration and RBC shape, which makes it somehow more reliable. Both the method of haemoglobin measurement and blood sample source can affect the measured haemoglobin concentration. The cyanmethemoglobin and the HemoCue system are the methods generally recommended for use in surveys to determine the population prevalence of anaemia. ${ }^{15,16}$ The cyanmethemoglobin measurement is the reference laboratory method for the quantitative determination of haemoglobin and is used for comparison and standardization of other methods. ${ }^{15,16}$ The HemoCue system is based on the cyanmethemoglobin method and has been shown to be stable and durable in field settings. ${ }^{16,17}$ Haematocrit or packed cell volume is a commonly performed clinical assessment frequently used in surveys of anaemia because of its simplicity and the widespread availability of the necessary equipment. $\mathrm{Hb}$ is considered to be superior to Hct for the purpose of monitoring anaemia as it has an internationally accepted reference standard calibrator for cyanmethemoglobin method. ${ }^{18,19}$ Automated cell counters now also use Sodium lauryl sulphate instead of toxic reagents (cyanmethemoglobin method). ${ }^{20,21}$ In resource poor settings where automated haematology analysers are not available, the manual cyanmethemoglobin method is often used for Hb estimation. Nevertheless, this method is time consuming and its disposal may create a problem due to large volumes of reagent which contains cyanide constitute a potential bio toxic hazard. ${ }^{20,21}$ In situations where limited resources are available, and the technical support is poor, a simple screening tool is likely to perform better than sophisticated methods that depend on correct dilutions and preparation of standards. As per the literature, microhaematocrit method has an adequate level of accuracy and precision for clinical utility and therefore in many settings where automated methods for $\mathrm{Hb}$ determinations are not available, $\mathrm{Hb}$ values are estimated using observed Hct levels. In general, in a rural setting, the running costs for Hct are very low and therefore in studies involving large populations it is cheaper to measure Hct. ${ }^{22}$ Further it is a less hazardous method that can be performed by less qualified personnel.

\section{Three-fold conversion between $\mathrm{Hb}$ and $\mathrm{Hct}$}

It is generally assumed that the conversion from $\mathrm{Hb}$ to Hct is pretty straightforward. Using the Hct value, there is a rough conversion factor of 3 which converts the Hct value to approximate $\mathrm{Hb}$ level. ${ }^{4,23,24} \mathrm{Hb}$ and $\mathrm{Hct}$ and the crude relationship between $\mathrm{Hb}$ and Hct levels may be modified due to several factors. The literature has highlighted the fact that, it may vary with age, sex, season of survey and disease conditions such as malaria. ${ }^{18,19,25-30}$ It could be the case that obtaining a single conversion factor is not feasible, as the relationship depends on the prevalence of anaemia in each population and on the type of anaemia pre-dominating within it. Various studies have been done on this matter in various countries and they show that the assessment of anaemia using the 3-fold conversion between $\mathrm{Hb}$ and $\mathrm{Hct}$ has become a debatable issue with some studies showing positive correlation and some showing absence of any correlation. ${ }^{19,27-29,31}$

Only one study has been done regarding validity of this conversion in pregnant females which shows poor correlation of this conversion factor. ${ }^{30}$ Therefore, before commenting on reliability of this conversion factor and the potential for further improvements in the conversion factor certainly merits further investigation and analysis in pregnancy.

The objectives of the present study were:

- To assess the validity of the threefold conversion formula between haemoglobin and haematocrit for the determination of anaemia in 3rd trimester of pregnancy.

- To know the prevalence of anaemia with its grading into mild, moderate and severe in pregnancy $\left(3^{\text {rd }}\right.$ trimester) in area of Himachal Pradesh around Maharishi Markandeshwar Medical College and Hospital, Solan, Himachal Pradesh, India. 
- To know whether mild, moderate or severe anaemia in $3^{\text {rd }}$ trimester pregnancy is associated with less birth weight, head circumference, chest circumference, mid-arm circumference and/or length of the newborn.

\section{METHODS}

This prospective cross-sectional study was done w.e.f March 2017, in Maharishi Markandeshwar Medical College and Hospital, Solan, Himachal Pradesh, India. Four hundred pregnant women who gave birth at the Obstetrics department and their newborns were included in this study.

\section{Inclusion criteria}

All singleton pregnancies with gestational age of more than 37 completed weeks, admitted in the $3^{\text {rd }}$ trimester for the delivery of baby in Obstetrics and Gynaecology Department of Maharishi Markandeshwar Hospital and Medical College, Solan, Himachal Pradesh.

\section{Exclusion criteria}

- Multiple pregnancies

- Gravidae 4 or more, pregnancy in $1^{\text {st }}$ or $2^{\text {nd }}$ trimester

- Positive history of smoking cigarettes, tobacco use, alcohol or narcotic use

- Age less than 18 years and more than 40 years

- History of any chronic illness, other diagnosed causes of non-nutritional anaemia

- Liver, kidney and/or heart disease, diabetes, hypertension, severe sepsis

- History of menorrhagia, any visible blood loss or blood transfusion in last 12 months

- Babies born with congenital malformations

\section{Procedure}

A written and informed consent was obtained from each participant/family members and an interviewer administered questionnaire was filled before starting the procedure/study. Venous blood samples of the cases were collected under minimal stasis in Sodium EDTA (ethylene diamine tetra acetic acid of $2 \mathrm{mg} / \mathrm{ml}$ concentration) containing glass tubes. These tubes were adequately labelled and immediately sent to laboratory. These samples were stored at $4^{0} \mathrm{C}$ and processed within 6 hours of taking the sample.

The estimation of hematocrit was done by microhematocrit method, as recommended by WHO.20 Reporting was done in percentage units. In each case this hematocrit value was divided by 3 to get a value which was denoted as calculated hemoglobin and its reporting was done in grams/decilitre $(\mathrm{gm} / \mathrm{dl})$. Estimation of hemoglobin was done by automated blood cell analyzer based on cyanmethemoglobin method from the same samples. The values were denoted as measured hemoglobin and reporting was done in $\mathrm{gm} / \mathrm{dl}$.

Anaemia was defined and classified according to WHO guidelines as the presence of an $\mathrm{Hb}$ level of less than 11.0 gm/dl during pregnancy. ${ }^{3-5}$ All the anthropometry parameters of neonates were done at 24-48 hours of life and were taken as per guidelines given by WHO. ${ }^{32}$

\section{Statistical methods}

IBM SPSS statistics software and Analyse-it statistics software for Microsoft excel 4.91.3 was used for the study. Continuous variables were expressed as standard descriptive statistical calculations (mean, median, mode, standard deviation etc.). An assessment of the normality of data, wherever required was done by Shapiro-Wilk test. Welch's ANOVA test, Post Hoc Games Howell multiple comparison test and Bland Altman limits of agreement method was used in this study. In Bland Altman method, bias and precision estimates of $\pm 1 \mathrm{gm} / \mathrm{dl}$ and $\pm 1 \mathrm{gm} / \mathrm{dl}$, respectively, were established a priori as the maximum parameters that would indicate acceptable agreement between methods and precision of the difference. . $^{33,34}$

\section{RESULTS}

This study included a total of 400 subjects and their respective newborns. Minimum and maximum maternal age was 19 years and 38 years respectively. Mean and median age was 25.2 years and 25 years respectively with standard deviation of 3.5 years.

Table 1: Categorization of cases according to measured haemoglobin levels.

\begin{tabular}{|ll|llllll} 
Variable groups & $\begin{array}{l}\text { Number of } \\
\text { cases }(\%)\end{array}$ & $\begin{array}{l}\text { Minimum } \\
\text { haemoglobin } \\
(\mathrm{g} / \mathrm{m} / \mathrm{dl})\end{array}$ & $\begin{array}{l}\text { Maximum } \\
\text { Haemoglobin } \\
(\mathrm{gm} / \mathrm{dl})\end{array}$ & $\begin{array}{l}\text { Median } \\
(\mathrm{gm} / \mathrm{dl})\end{array}$ & $\begin{array}{l}\text { Mode } \\
(\mathrm{gm} / \mathrm{dl})\end{array}$ & $\begin{array}{c}\text { Mean } \\
(\mathrm{gm} / \mathrm{dl})\end{array}$ & $\begin{array}{l}\text { Standard } \\
\text { Deviation } \\
(\mathrm{gm} / \mathrm{dl})\end{array}$ \\
\hline Anaemic & $215(53.75)$ & 05.00 & 10.90 & 09.80 & 10.30 & 09.43 & 01.26 \\
\hline Non- anaemic & $185(46.25)$ & 11.00 & 14.60 & 12.00 & 11.40 & 12.13 & 00.88 \\
\hline Mild anaemia & $89(22.25)$ & 10.00 & 10.90 & 10.50 & 10.30 & 10.47 & 00.29 \\
\hline Moderate anaemia & $113(28.25)$ & 07.10 & 09.90 & 09.20 & 09.90 & 08.96 & 00.85 \\
\hline Severe anaemia & $13(3.25)$ & 05.00 & 06.90 & 06.60 & 06.90 & 06.34 & 00.67 \\
\hline Total cases & $400(100)$ & 05.00 & 14.60 & 10.80 & 11.40 & 10.68 & 01.74 \\
\hline
\end{tabular}


Table 2: Anthropometric parameters of new-borns.

\begin{tabular}{|llllllll|}
\hline Variable & $\begin{array}{l}\text { Number of } \\
\text { cases }(\mathrm{n})\end{array}$ & Minimum & Maximum & Median & Mode & Mean & SD \\
\hline Length $(\mathrm{cm})$ & 400 & 41.00 & 55.50 & 49.10 & 50.00 & 49.15 & 02.47 \\
\hline Head circumference $(\mathrm{cm})$ & 400 & 30.50 & 39.00 & 34.20 & 34.00 & 34.19 & 01.30 \\
\hline Chest circumference $(\mathrm{cm})$ & 400 & 27.50 & 36.80 & 32.10 & 31.20 & 32.09 & 01.44 \\
\hline Birth weight $(\mathrm{gm})$ & 400 & 1770.00 & 4055.00 & 2772.50 & 2800.00 & 2781.20 & 0401.10 \\
\hline Mid-arm circumference $(\mathrm{cm})$ & 400 & 07.90 & 14.00 & 10.20 & 10.50 & 10.34 & 01.12 \\
\hline
\end{tabular}

Out of total of 400 cases, $209(52.25 \%)$ were normal vaginal deliveries, $64(16 \%)$ were elective lower segment caesarean section (LSCS) cases, 103 (25.75\%) were emergency LSCS cases, $1(0.25 \%)$ was by forceps assisted vaginal delivery and $23(5.75 \%)$ were vacuum assisted vaginal deliveries. LSCS constituted 167 cases i.e. $41.75 \%$ of the total. Out of a total of 400 new-borns, 175 new-borns $(43.75 \%)$ were male and the rest females. 215 maternal cases were anaemic among which $41.39 \%$ were mildly anaemic, $52.56 \%$ were moderately anaemic and $6.05 \%$ were severely anaemic. Detailed characteristics of the subjects and new-borns are as outlined in Table 1 and 2.

\section{Comparison between measured haemoglobin and calculated haemoglobin (all groups)}

Comparison of means by paired (dependent) sample $\mathrm{T}$ test showed significant difference between the measured $\mathrm{Hb}$ and calculated $\mathrm{Hb}(\mathrm{p}=0.005)$.
A scatter diagram of the measured haemoglobin and calculated haemoglobin was made. Most of $\mathrm{Hb}$ values are seen closely clustered around and also both distributed above and below the line of equality in a linear fashion, though a few outliers are also seen. Pearson's correlation coefficient (r) was 0.938 , with a significance level of $\mathrm{p}$ $<0.0001$, and $95 \%$ confidence interval (CI) for $r$ of 0.925 to 0.948 .

The correlation analysis results tell that: the calculated $\mathrm{Hb}$ is very highly and positively associated with the measured $\mathrm{Hb}$; the probability that this association was due to chance is less than 1 in 10,000; and when these methods are used in similar conditions, we can be confident that the $r$ will be between 0.925 and $0.948 .{ }^{35}$ However, the strong correlation does not tell us about agreement between the methods. Bland Altman method was used for this purpose.

Table 3: Descriptive comparison of measured and calculated $\mathrm{Hb}$ values.

\begin{tabular}{|lllllll|} 
& N & Range & Minimum & Maximum & Mean & SD \\
\hline Measured $\mathrm{Hb}^{*}$ & 400 & 9.60 & 5.00 & 14.60 & 10.68 & 1.74 \\
\hline Calculated $\mathrm{Hb}^{*}$ & 400 & 12.20 & 3.67 & 15.87 & 10.77 & 1.85 \\
\hline Valid N (list wise) & 400 & & & & & \\
\hline$*$ Hb is in $\mathrm{gm} / \mathrm{dl}$ & & & & & &
\end{tabular}

$* \mathrm{Hb}$ is in $\mathrm{gm} / \mathrm{dl}$

While interpreting Bland Altman plot, the bias for each paired measurement point varied (bias is both positive and negative), across all paired measurements the average difference was $0.091 \mathrm{gm} / \mathrm{dl}$, the value that would be reported as the bias for this data set. This bias is less than the priori criteria of $1 \mathrm{gm} / \mathrm{dl}$. The confidence limit is $2.529 \mathrm{gm} / \mathrm{dl}$ which is more than a priori criterion of 1 $\mathrm{gm} / \mathrm{dl}$.

So, one can conclude that though the accuracy of the test method is acceptable, but repeatability is not acceptable. It is also noted that 21 data points exceed the limits of agreement; 10 exceed the upper limit and 11 exceeds the lower limit. Percentage error is $23.68 \%$ which means that haemoglobin differences between two methods depend upon the haemoglobin value i.e. severity of anaemia.

\section{Comparison between measured and calculated haemoglobin (no anaemia group)}

Pearson's correlation coefficient ( $r$ ) was 0.808 , with a significance level of $\mathrm{p}<0.0001$, and $95 \%$ confidence interval $(\mathrm{CI})$ for $\mathrm{r}$ of 0.751 to 0.853 . The bias was 0.089 $\mathrm{gm} / \mathrm{dl}$ which is less than the priori criteria of $1 \mathrm{gm} / \mathrm{dl}$. The confidence limit is $2.75 \mathrm{gm} / \mathrm{dl}$ which is more than a priori criterion of $1 \mathrm{gm} / \mathrm{dl}$. Percentage error is $22.67 \%$. So, one can conclude that though the accuracy of the test method is acceptable, but repeatability is not acceptable. 


\section{Comparison between measured and calculated haemoglobin (Mild anaemia group)}

Pearson's correlation coefficient (r) was 0.215 , with a significance level of $\mathrm{p}<0.0001$, and $95 \%$ confidence interval (CI) for $r$ of 0.007 to 0.405 . The bias was 0.085 $\mathrm{gm} / \mathrm{dl}$ which is less than the priori criteria of $1 \mathrm{gm} / \mathrm{dl}$.

Table 4: Bland Altman analysis of the measured and calculated haemoglobin.

\begin{tabular}{|llll|}
\hline Parameter & Estimate & $95 \%$ CI & SE \\
\hline Mean difference & 0.091 & $\begin{array}{l}0.0274 \text { to } \\
0.1542\end{array}$ & 0.0323 \\
\hline 95\% lower LoA & -1.174 & $\begin{array}{l}-1.2822 \\
-1.0652\end{array}$ & 0.0552 \\
\hline 95\% upper LoA & 1.355 & $\begin{array}{l}1.2468 \text { to } \\
1.4637\end{array}$ & 0.0552 \\
\hline SD & 0.645 & & \\
\hline
\end{tabular}

CI: Confidence interval, SD: Standard deviation; SE: Standard error; LoA: Limits of agreement; ${ }^{*} \mathrm{Hb}$ is in $\mathrm{gm} / \mathrm{dl}$

The confidence limit is $1.82 \mathrm{gm} / \mathrm{dl}$ which is more than a priori criterion of $1 \mathrm{gm} / \mathrm{dl}$. Percentage error is $17.38 \%$. So, one can conclude that though the accuracy of the test method is acceptable, but repeatability is not acceptable.
Comparison between measured and calculated haemoglobin (moderate anaemia group)

Pearson's correlation coefficient (r) was 0.784 , with a significance level of $\mathrm{p}<0.0001$, and $95 \%$ confidence interval (CI) for $r$ of 0.700 to 0.846 . The bias was 0.086 $\mathrm{gm} / \mathrm{dl}$ which is less than the priori criteria of $1 \mathrm{gm} / \mathrm{dl}$. The confidence limit is $2.49 \mathrm{gm} / \mathrm{dl}$ which is more than a priori criterion of $1 \mathrm{gm} / \mathrm{dl}$. Percentage error is $27.79 \%$. So, one can conclude that though the accuracy of the test method is acceptable, but repeatability is not acceptable.

\section{Comparison between measured and calculated haemoglobin (severe anaemia group)}

Pearson's correlation coefficient (r) was 0.667 , with a significance level of $\mathrm{p}<0.0001$, and $95 \%$ confidence interval (CI) for $r$ of 0.183 to 0.891 . The bias was 0.195 $\mathrm{gm} / \mathrm{dl}$ which is less than the priori criteria of $1 \mathrm{gm} / \mathrm{dl}$. The confidence limit is $3.835 \mathrm{gm} / \mathrm{dl}$ which is more than a priori criterion of $1 \mathrm{gm} / \mathrm{dl}$. Percentage error is $60.49 \%$. So, one can conclude that though the accuracy of the test method is acceptable, but repeatability is not acceptable. Association of severity of anaemia in $3^{\text {rd }}$ trimester pregnancy with birth weight, head circumference, chest circumference, mid-arm circumference and/or length of the new-born.

Table 5: Correlation between measured $\mathrm{Hb}$ and various anthropometry parameters.

\begin{tabular}{|c|c|c|c|c|c|c|}
\hline & $\begin{array}{l}\text { Chest } \\
\text { circumference }(\mathrm{cm})\end{array}$ & $\begin{array}{l}\text { Mid-arm } \\
\text { circumference }(\mathrm{cm})\end{array}$ & $\begin{array}{l}\text { Head } \\
\text { Circumference }(\mathrm{cm}\end{array}$ & $\begin{array}{l}\text { Length } \\
(\mathrm{cm})\end{array}$ & $\begin{array}{l}\text { Weight } \\
\text { (gm) }\end{array}$ & \\
\hline Measured $\mathrm{Hb}^{*}$ & 0.478 & 0.464 & 0.471 & 0.473 & 0.551 & Pearson's R \\
\hline Measured $\mathrm{Hb}^{*}$ & 0.466 & 0.460 & 0.465 & 0.443 & 0.554 & Spearman's RS \\
\hline Measured $\mathrm{Hb}^{*}$ & 0.330 & 0.333 & 0.334 & 0.315 & 0.407 & Kendall's TAU \\
\hline
\end{tabular}

$* \mathrm{Hb}$ is in $\mathrm{gm} / \mathrm{dl}$

By seeing these parameters, we can say that weight and length visibly decrease as the severity of anaemia increases. $\mathrm{HC}, \mathrm{CC}$ and MAC also show decrease especially in moderate and severe anaemia groups. As assumption of homogeneity of variances was violated, Welch's ANOVA (Analysis of variance between groups) test was used in the statistical comparisons of groups and Post Hoc Games Howell multiple comparison test was utilized in the comparison of subgroups. $\mathrm{p}$ value of less than 0.05 and 0.01 was treated as significant in Welch's ANOVA test and Post Hoc Games Howell multiple comparison test respectively.

Table 6: Neonatal anthropometric parameters in no anaemia and various anaemia groups.

\begin{tabular}{|lllll|}
\hline Variable & $\begin{array}{l}\text { No anaemia } \\
\text { Group }\end{array}$ & $\begin{array}{l}\text { Mild anaemia } \\
\text { group }\end{array}$ & $\begin{array}{l}\text { Moderate } \\
\text { anaemia group }\end{array}$ & $\begin{array}{l}\text { Severe anaemia } \\
\text { group }\end{array}$ \\
\hline Weight* Mean (SD) & $2956.49(369.15)$ & $2803.43(282.685)$ & $2536.50(368.726)$ & $2261.92(268.022)$ \\
\hline Length* Mean (SD) & $50.1373(2.09125)$ & $49.0596(2.08641)$ & $48.0027(2.49752)$ & $45.6000(2.05629)$ \\
\hline Head circumference* Mean (SD) & $34.6773(1.23391)$ & $34.2079(1.12938)$ & $33.5531(1.15380)$ & $32.5923(0.74326)$ \\
\hline $\begin{array}{l}\text { Chest circumference* Mean (SD) } \\
\text { Mid-Arm circumference* }\end{array}$ & $32.6897(1.27067)$ & $31.9551(1.24024)$ & $31.4850(1.36364)$ & $29.9308(1.04034)$ \\
Mean (SD) & $10.7432(1.06830)$ & $10.4101(0.81937)$ & $9.7779(1.04631)$ & $8.9077(1.05551)$ \\
\hline
\end{tabular}

*Weight is in gram. Length, Head circumference, chest circumference, mid-arm circumference is given in centimetre 


\section{Anthropometry parameters and Anaemia status comparison}

The Welch ANOVA analysis tells us that the differences between increasing $\mathrm{Hb}$ concentrations in 3rd trimester pregnancy and all anthropometric parameters of newborns are statistically significant. Using the same data and same 4 groups (no anaemia, mild, moderate and severe anaemia) Welch ANOVA was further developed with a post hoc Games Howell test. While taking weight as dependent variable, relationship between weight and $\mathrm{Hb}$ was not statistically significant between moderate anaemia and severe anaemia group $(p=0.017)$. Rest of combinations were statistically significant.

Table 7: Welch ANOVA test with weight (gm) as dependent variable.

\begin{tabular}{|lllll|}
\hline & Statistic $^{\mathrm{a}}$ & dff1 & df2 & Sig. \\
\hline Welch & 45.763 & 3 & 57.235 & 0.000 \\
\hline Brown-Forsythe & 52.908 & 3 & 163.167 & 0.000 \\
\hline${ }^{\text {a} A s y m p t o t i c a l l y ~ F ~ d i s t r i b u t e d . ~}$ & & &
\end{tabular}

While taking length as dependent variable, statistical difference was seen in every group. While taking head circumference as dependent variable, relationship between $\mathrm{HC}$ and $\mathrm{Hb}$ was marginally not statistically significant between no anaemia and mild anaemia group $(\mathrm{p}=0.011)$.

Table 8: Welch ANOVA test with length $(\mathrm{cm})$ as dependent variable.

\begin{tabular}{|lllll|} 
& Statistic $^{\mathrm{a}}$ & df1 & df2 & Sig. \\
Welch & 33.585 & 3 & 55.145 & .000 \\
\hline Brown-Forsythe & 34.516 & 3 & 117.978 & .000 \\
\hline
\end{tabular}

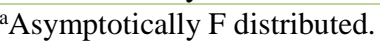

Rest of combinations were statistically significant. While taking chest circumference as dependent variable, relationship between $\mathrm{CC}$ and $\mathrm{Hb}$ was not statistically significant between moderate anaemia and mild anaemia group ( $\mathrm{p}=0.054)$. Rest of combinations were statistically significant.

Table 9: Welch ANOVA test with head circumference (cm) as dependent variable.

\begin{tabular}{|c|c|c|c|c|}
\hline & Statistic ${ }^{a}$ & df1 & df2 2 & Sig. \\
\hline Welch & 39.166 & 3 & 59.554 & .000 \\
\hline Brown-Forsythe & 37.269 & 3 & 232.814 & .000 \\
\hline
\end{tabular}

Table 10: Welch ANOVA test with chest circumference $(\mathrm{cm})$ as dependent variable.

\begin{tabular}{|lllll|}
\hline & Statistic $^{\mathrm{a}}$ & df1 & df2 & \multicolumn{1}{c|}{ Sig. } \\
\hline Welch & 39.162 & 3 & 56.449 & .000 \\
\hline Brown-Forsythe & 38.190 & 3 & 154.861 & .000 \\
\hline aAsymptotically F distributed. & & &
\end{tabular}

While taking MAC as dependent variable, relationship between MAC and $\mathrm{Hb}$ was not statistically significant between moderate anaemia and severe anaemia group $(\mathrm{p}=0.057)$ and also between no anaemia and mild anaemia group $(p=0.025)$. Rest of combinations were statistically significant.

Table 11: Welch ANOVA test with mid-arm circumference $(\mathrm{cm})$ as dependent variable.

\begin{tabular}{|lllll|}
\hline & Statistic $^{\mathrm{a}}$ & dff1 & df2 & Sig. \\
\hline Welch & 27.196 & 3 & 55.048 & .000 \\
\hline Brown-Forsythe & 30.976 & 3 & 83.677 & .000 \\
\hline
\end{tabular}

${ }^{a}$ Asymptotically F distributed.

\section{DISCUSSION}

\section{Anaemia}

Present study showed that $53.75 \%$ women in their $3^{\text {rd }}$ trimester were anemic, which closely mimic the WHO data but is about $11 \%$ more than the prevalence in Himachal Pradesh. ${ }^{36}$ In the present study mild, moderate and severe anaemic mothers were $22.25 \%, 28.25 \%$ and $3.25 \%$ respectively in comparison to Himachal data of $11.1 \%, 25.7 \%$ and $6.2 \%$ respectively. ${ }^{36}$ Present study shows more cases of mild anaemia and less of severe anaemia cases. Decrease in severe anaemia cases is a welcome sign but overall $53.75 \%$ cases of anaemia that too in $3^{\text {rd }}$ trimester is worrisome. More input both from the people and health care system including policy makers is required to decrease this high prevalence of anaemia. Comparing measured and calculated $\mathrm{Hb}$ : the mean measured $\mathrm{Hb}$ value (obtained from automated blood cell analyzer method) was $10.68 \mathrm{gm} / \mathrm{dl}$ while the corresponding value derived from 3-fold conversion of Hct i.e. calculated $\mathrm{Hb}$ was $10.77 \mathrm{gm} / \mathrm{dl}$. Pearson's correlation coefficient (r) was 0.938 . But on doing limits of agreement method by Bland Altman, though the accuracy (bias) of the test method was acceptable but repeatability (precision) was not acceptable. So, both methods are not interchangeable in $3^{\text {rd }}$ trimester of pregnancy. On comparing both methods of measuring $\mathrm{Hb}$ in different groups of no anaemia, mild anaemia, moderate anaemia and severe anaemia the results were the same as accuracy (bias) was acceptable but repeatability (precision) was not acceptable in all these cases. In severe anaemia group repeatability was the worst.

Various studies have been done on this matter in various countries and most of them they show that the assessment of anaemia using the 3-fold conversion between $\mathrm{Hb}$ and Hct is not accurate with very few show that this conversion is acceptable. ${ }^{19,27-29,31}$ Only one study has been done in India regarding validity of this conversion in pregnant females which shows poor correlation of this conversion factor. ${ }^{30}$ Therefore the standard 3-fold conversion between the two measures cannot be 
considered as valid for the assessment of anaemia in the $3^{\text {rd }}$ trimester pregnancy.

Multiple factors may be the cause of this like age and seasonal variations, physiological changes during pregnancy, errors of microhematocrit procedure such as errors in filling or sealing, reading errors and packing errors during the microhematocrit procedure etc. Also, there is a possibility of other unknown environmental factors and subject's differences being the cause. So, due to the lack of agreement, the commonly assumed equivalent cut-off points for anaemia definitions which are even recommended by WHO need to be re-evaluated. This information is also of relevance for both clinical diagnosis and management of anaemia cases, as well as for descriptive and intervention studies on anaemia. Also, the imprecision in measurement of $\mathrm{Hb}$ by the Hct method may result in variations in calculation of mean corpuscular volume and $\mathrm{MCHC}$ which are important parameters in classification and thereby management of anaemia.

Effect of anaemia on newborn anthropometry: In this study while comparing anthropometric measurements between mild/ no anaemia group with severe anaemia group we found that all measurements for weight, length, chest circumference, head circumference and mid-arm circumference were less in severe anaemia group and this difference was statistically significant. Thus the present study showed that birth weight, height, head circumference, chest circumference and mid-arm circumference were affected by third trimester hemoglobin that too the most in severe anaemia cases which is consistent with previous studies. ${ }^{12,37-40}$ The association between maternal $\mathrm{Hb}$ and birth weight follows a U-shaped curve. ${ }^{41}$

$\mathrm{Hb}>13.5 \mathrm{gm} / \mathrm{dl}$ or $>3$ standard deviations higher than the mean of the reference population (i.e., a $\mathrm{Hb}$ concentration of $>15.0 \mathrm{gm} / \mathrm{dl}$ or a Hct of $>45.0 \%$ ), is unusual and suggests inadequate plasma volume expansion (which can be associated with pregnancy problems including pre-eclampsia, poor fetal growth and preterm deliveries). ${ }^{42,43}$ In the present study we had only 12 cases (3\%) with $\mathrm{Hb}>13.5 \mathrm{gm} / \mathrm{dl}$ and none $>14.6 \mathrm{gm} / \mathrm{dl}$. Also, we didn't include preterm delivery cases in our study. May be this is the reason we did not get less anthropometric parameters in no anaemia group.

Present study was conducted in a tertiary care hospital. Since many women in Himachal Pradesh deliver at home, the burden of anaemia can be expected to be much higher outside the hospital setting. By improving food intake, socioeconomic condition, literacy, qualitative antenatal care, early referral of risky cases, provision of iron and folic acid supplementation, parenteral iron therapy and blood transfusion whenever necessary we can reduce the incidence of anaemia in pregnancy and thereby reducing the ill effects on newborns.
Study limitation: this study was performed in a single center that too a tertiary referral center. Also, the sample size is not so big; it may not be representative of the whole population of the state or nation. Secondly, mothers were not categorized for some other maternal factors like low height and body mass index, which could contribute to neonatal anthropometric parameters. Also, we could not assess the hemoglobin levels in mothers during the first and second trimester and umbilical cord $\mathrm{Hb}$. Not performing serum folate and Vitamin B12 levels, peripheral blood film microscopy and serum iron profile (for the confirmation and differentiation of anaemia) due to financial constraints was another shortcoming.

\section{ACKNOWLEDGMENTS}

We thank the nursing staff of both Obstetrics and Paediatrics Department for their invaluable help in assisting with this project.

Funding: No funding sources

Conflict of interest: None declared

Ethical approval: The study was approved by the Institutional Ethics Committee

\section{REFERENCES}

1. World Health Organization. The global prevalence of anaemia in 2011. Available at http://apps.who.int/iris/bitstream/10665/177094/1/97 89241564960_eng.pdf

2. DeMaeyer EM, Dallman P, Gurney JM, Hallberg L, Sood SK, Srikantia SG, World Health Organization. Preventing and controlling iron deficiency anaemia through primary health care: a guide for health administrators and programme managers. 1989. Available

http://www.who.int/nutrition/publications/micronutri ents/anaemia_iron_deficiency/9241542497.pdf

3. World Health Organisation. Haemoglobin concentrations for the diagnosis of anaemia and assessment of severity. Vitamin and Mineral Nutrition Information System. Geneva: World Health Organization. 2011. Available at http://apps.who.int/iris/bitstream/10665/85839/3/WH O_NMH_NHD_MNM_11.1_eng.pdf?ua=1

4. World Health Organization. Nutritional anaemias: report of a WHO scientific group [meeting held in Geneva from 13 to 17 March 1967]. Available at http://apps.who.int/iris/bitstream/10665/40707/1/WH O_TRS_405.pdf

5. World Health Organization. The management of nutrition in major emergencies. World Health Organization; 2000.

6. Centers for Disease Control (CDC). CDC criteria for anemia in children and childbearing-aged women. MMWR. Morbidity and mortality weekly report. 1989;38(22):400. 
7. Milman N. Anemia: still a major health problem in many parts of the world! Ann Hemato. 2011;90(4):369-77.

8. Breymann C, Bian XM, Blanco-Capito LR, Chong C, Mahmud G, Rehman R. Expert recommendations for the diagnosis and treatment of iron-deficiency anemia during pregnancy and the postpartum period in the Asia-Pacific region. $\mathrm{J}$ Perinatal Med. 2011;39(2):113-21.

9. Breymann C. Iron supplementation during pregnancy. Fetal and maternal medicine review. 2002;13(1):1-29.

10. Perewusnyk G, Huch R, Huch A, Breymann C. Parenteral iron therapy in obstetrics: 8 years' experience with iron-sucrose complex. British J Nutr. 2002;88(01):3-10.

11. Haas JD, Brownlie T. Iron deficiency and reduced work capacity: a critical review of the research to determine a causal relationship. J Nutr. 2001;131(2):676S-90S.

12. Telatar B, Comert S, Vitrinel A, Erginoz E, Akin Y. The effect of maternal anemia on anthropometric measurements of newborns. Saudi Med J. 2009;30(3):409-12.

13. Kalaivani K. Prevalence and consequences of anaemia in pregnancy. Indian $\mathbf{J}$ Med Res. 2009;130(5):627-33.

14. World Health Organization. Iron deficiency anaemia: assessment, prevention and control: a guide for programme managers. 2001.

15. National Committee for Clinical Laboratory Standards. Reference and Selected Procedures for the Quantitative Determination of Haemoglobin in Blood: approved standards. $2^{\text {nd }}$ ed. Villanova, PA, National Committee for Clinical Laboratory Standards, 1994.

16. Von Schenck H, Falkensson M, Lundberg B. Evaluation of "HemoCue", a new device for determining hemoglobin. Clin Chem. 1986;32(3):526-9.

17. Johns WL, Lewis SM. Primary health screening by haemoglobinometry in a tropical community. Bull World Health Organization. 1989;67(6):627.

18. Keen ML. Hemoglobin and hematocrit: an analysis of clinical accuracy-case study of the anemic patient. Nephrol Nur J. 1998;25(1):83.

19. Quintó L, Aponte JJ, Menéndez C, Sacarlal J, Aide P, Espasa M, et al. Relationship between haemoglobin and haematocrit in the definition of anaemia. Tropical Med Int Health. 2006;11(8):1295302.

20. Shah VB, Shah BS, Puranik GV. Evaluation of noncyanide methods for hemoglobin estimation. Indian $\mathrm{J}$ Pathol Microbiol. 2011;54(4):764.

21. Chakravarthy VK, Chandra DN, Prasanna BS, Rao TJ, Rao DR. Haemoglobin estimation by noncyanide methods. J Clin Diag Res. 2012;6(6).

22. World Health Organization (WHO). Recommended method for the determination of packed cell volume by centrifugation (prepared by Expert Pane on cytometry of the International Council for WHO/DIL/00. WHO, Geneva. 2000;1:1-9.

23. Hillman RS, Finch CA. Red cell manual. $6^{\text {th }}$ ed. Philadelphia: FA Davis Company; 1994.

24. Bain BJ, Bates I. Basic haematological techniques. In: Lewis SM, Bain BJ, Bates I, editors. Dacie and Lewis practical haematology. $9^{\text {th }}$ ed. Edinburgh: Churchill Livingstone; 2001:19-46.

25. Graitcer PL, Goldsby JB, Nichaman MZ. Hemoglobins and hematocrits: are they equally sensitive in detecting anemias? Am J Clin Nutr. 1981;34(1):61-4.

26. De Benoist B, McLean E, Egli I, Cogswell M, Cogswell M. WHO global database on anaemia. Geneva: WHO. 2008:1993-2005.

27. Carneiro IA, Drakeley CJ, Owusu-Agyei S, Mmbando B, Chandramohan D. Haemoglobin and haematocrit: is the threefold conversion valid for assessing anaemia in malaria-endemic settings? Malaria J. 2007;6(1):67.

28. Rodríguez-Morales AJ, Sánchez E, Arria M, Vargas M, Piccolo C, Colina R, et al. Haemoglobin and haematocrit: the threefold conversion is also nonvalid for assessing anaemia in Plasmodium vivax malaria-endemic settings. Malaria J. 2007;6(1):1.

29. Lee SJ, Stepniewska K, Anstey N, Ashley E, Barnes $\mathrm{K}$, Binh TQ, et al. The relationship between the haemoglobin concentration and the haematocrit in Plasmodium falciparum malaria. Malaria J. 2008;7(1):149.

30. Amarasiri AM, Wickramaratne KA. Assessing the validity of the threefold conversion between hemoglobin and hematocrit for the determination of anemia in pregnancy. In KDU International Research Conference, 2014. 2015:24.

31. Ekwochi U, Ifediora C, Osuorah DC, Ndu IK, Amadi OF, Odetunde IO. Evaluation of the packed cell volume (PCV) as a potential screening tool for iron deficiency anaemia among under-5 children in a resource limited setting. J Exp Res. 2015;3(2):81-5.

32. de Onis M, Onyango AW, Van den Broeck J, Chumlea CW, Martorell R. Measurement and standardization protocols for anthropometry used in the construction of a new international growth reference. Food Nutr Bull. 2004; 25(1):S27-36.

33. Medicare M. CLIA programs; regulations implementing the Clinical Laboratory Improvement Amendments of 1988 (CLIA)-HCFA. Final rule with comment period. Fed Regist. 1992;57(40):7002-186.

34. Radtke H, Polat G, Kalus U, Salama A, Kiesewetter H. Hemoglobin screening in prospective blood donors: comparison of different blood samples and different quantitative methods. Transfusion Apheresis Sci. 2005;33(1):31-5.

35. Hinkle DE, Wiersma W, Jurs SG. Applied statistics for the behavioral sciences. $5^{\text {th }}$ ed. Boston: Houghton Mifflin; 2003.

36. International Institute for Population Sciences (IIPS), 2014. District Level Household and Facility survey (DLHS-4), 2012-13: India. Himachal Pradesh: 
Mumbai:

IIPS.

Available

http://rchiips.org/pdf/dlhs4/report/HP.pdf

37. Yi SW, Han YJ, Ohrr H. Anemia before pregnancy and risk of preterm birth, low birth weight and smallfor-gestational-age birth in Korean women. Eu J Clin Nutr. 2013;67(4):337-42.

38. Bora R, Sable C, Wolfson J, Boro K, Rao R. Prevalence of anemia in pregnant women and its effect on neonatal outcomes in Northeast India. J Maternal-Fetal Neonatal Med. 2014;27(9):887-91.

39. Godhia M, Nigudkar M, Desai R. Anthropometric indices of their full-term and pre-term newborns. Pak J Nutr. 2012;11(4):343-9.

40. Hadipour R, Norimah AK, Poh BK, Firoozehchian F, Hadipour R, Akaberi A. Haemoglobin and serum ferritin levels in newborn babies born to anaemic Iranian women: A cross-sectional study in an Iranian hospital. Pak J Nutr. 2010;9(6):562-6.
41. Breymann C. Iron deficiency anemia in pregnancy. Expert Rev Obstet Gynecol. 2013;8(6):587-96.

42. Pavord S, Hunt B, editors. The obstetric hematology manual. Cambridge University Press; 2010.

43. Iron DA. Recommendations to prevent and control iron deficiency in the United States. MMWR: Morbidity and Mortality Weekly Report. 1998;47:129.

Cite this article as: Behal M, Vinayak R, Sharma A. Maternal anaemia and its effects on neonatal anthropometric parameters in patients attending a tertiary care institute of Solan, Himachal Pradesh, India. Int J Reprod Contracept Obstet Gynecol 2018;7:552-60. 